Wright State University

CORE Scholar

7-1-2007

\title{
Electron and Hole Traps in N-Doped ZnO Grown on p-Type Si by Metalorganic Chemical Vapor Deposition
}

\author{
Z-Q. Fang \\ B. Claflin \\ David C. Look \\ Wright State University - Main Campus, david.look@wright.edu \\ Lei L. Kerr \\ Xiaonan Li
}

Follow this and additional works at: https://corescholar.libraries.wright.edu/physics

Part of the Physics Commons

\section{Repository Citation}

Fang, Z., Claflin, B., Look, D. C., Kerr, L. L., \& Li, X. (2007). Electron and Hole Traps in N-Doped ZnO Grown on p-Type Si by Metalorganic Chemical Vapor Deposition. Journal of Applied Physics, 102 (2), 23714. https://corescholar.libraries.wright.edu/physics/156

This Article is brought to you for free and open access by the Physics at CORE Scholar. It has been accepted for inclusion in Physics Faculty Publications by an authorized administrator of CORE Scholar. For more information, please contact library-corescholar@wright.edu. 


\title{
Electron and hole traps in N-doped ZnO grown on p-type Si by metalorganic chemical vapor deposition
}

\author{
Z.-Q. Fang, ${ }^{\text {a) }}$ B. Claflin, and D. C. Look \\ Semiconductor Research Center, Wright State University, Dayton, Ohio 45435 \\ and Materials and Manufacturing Directorate, Air Force Research Laboratory, \\ Wright-Patterson AFB, Ohio 45433 \\ Lei L. Kerr \\ Department of Paper and Chemical Engineering, Miami University, Oxford, Ohio 45056 \\ Xiaonan $\mathrm{Li}$ \\ National Renewable Energy Laboratory, Golden, Colorado 80401
}

(Received 2 March 2007; accepted 8 June 2007; published online 24 July 2007)

Electron and hole traps in $\mathrm{N}$-doped $\mathrm{ZnO}$ were investigated using a structure of $n^{+}-\mathrm{ZnO}: \mathrm{Al} / i-\mathrm{ZnO} / \mathrm{ZnO}: \mathrm{N}$ grown on a $p$-Si substrate by metalorganic chemical vapor deposition (for growth of the $\mathrm{ZnO}: \mathrm{N}$ layer) and sputtering deposition (for growth of the $i-\mathrm{ZnO}$ and $n^{+}-\mathrm{ZnO}: \mathrm{Al}$ layers). Current-voltage and capacitance-voltage characteristics measured at temperatures from 200 to $400 \mathrm{~K}$ show that the structure is an abrupt $n^{+}-p$ diode with very low leakage currents. By using deep level transient spectroscopy, two hole traps, $\mathrm{H} 3(0.35 \mathrm{eV})$ and $\mathrm{H} 4(0.48 \mathrm{eV})$, are found in the $p$-Si substrate, while one electron trap E3 $(0.29 \mathrm{eV})$ and one hole trap H5 $(0.9 \mathrm{eV})$ are observed in the thin ZnO:N layer. Similarities to traps reported in the literature are discussed. (C) 2007 American Institute of Physics. [DOI: 10.1063/1.2759181]

\section{INTRODUCTION}

Among possible acceptor dopants in $\mathrm{ZnO}$, nitrogen has been predicted to be the best candidate because it is about the same size as oxygen and thus should substitute easily without adding much strain. ${ }^{1,2}$ However, it has been very challenging to prepare $p$-type nitrogen doped $\mathrm{ZnO}(\mathrm{ZnO}: \mathrm{N})$, and most attempts, even successful ones, produce low hole concentrations and mobilities, and sometimes even instability. ${ }^{2,3}$ In fact, $\mathrm{ZnO}: \mathrm{N}$ will exhibit $n$-type conductivity when the growth conditions are not precisely controlled. For example, $\mathrm{ZnO}: \mathrm{N}$ films grown by metalorganic chemical vapor deposition (MOCVD) are $p$ type only if deposited at $\sim 400{ }^{\circ} \mathrm{C}$, and higher or lower growth temperatures lead to $n$-type material. ${ }^{4}$ Various growth conditions also can influence the presence of midgap impurities and point defects and such deep centers can produce undesired trapping and carrier recombination. In past years, deep level transient spectroscopy (DLTS) has been used to study traps (mainly electron traps) in $n$-type bulk $\mathrm{ZnO}$ grown by the hydrothermal, ${ }^{5}$ vapor-phase, ${ }^{6}$ and pressurized melt growth ${ }^{7}$ methods. In most of these cases, the DLTS test structures were Schottky-barrier diodes. A recent DLTS study has revealed deep acceptor states (hole traps) in $\mathrm{ZnO}$ single crystals using a novel $p-n$ junction formed by $\mathrm{N}^{+}$implantation. ${ }^{8}$ In that study, an $\mathrm{N}^{+}$-implanted $p$-ZnO layer was employed for injecting holes. Here, we present a DLTS investigation of a $\mathrm{ZnO}: \mathrm{N}$ thin film incorporated into a $p-n$ junction diode. The structure of our $p-n$ diode is composed of $n^{+}-\mathrm{ZnO}: \mathrm{Al} / i-\mathrm{ZnO} / \mathrm{ZnO}: \mathrm{N}$ layers grown onto a $p$-Si substrate. ${ }^{9}$ Although $p-n$ diodes are usu-

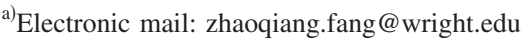

ally more difficult to fabricate than Schottky diodes, they have one big advantage for DLTS, namely, they allow observation of both hole and electron traps.

\section{EXPERIMENTS}

The growth procedure is detailed later. First of all, a nitrogen-doped $\mathrm{ZnO}$ thin layer, $\sim 270$-nm thick, was grown onto a $p$-Si substrate by low-pressure MOCVD. ${ }^{9}$ The precursors used in the growth were DEZ $\left[\left(\mathrm{C}_{2} \mathrm{H}_{5}\right)_{2} \mathrm{Zn}\right]$, oxygen, and dilute $\mathrm{NO}$ gas $(2$ wt $\% \mathrm{NO} / \mathrm{Ar})$. The carrier for all the precursors was $\mathrm{N}_{2}$ gas and the deposition temperature was $\sim 400{ }^{\circ} \mathrm{C}$. Next, a bilayer structure of $\sim 100$-nm-thick undoped $i-\mathrm{ZnO}$ layer and a similar thickness of $n^{+}-\mathrm{ZnO}: \mathrm{Al}$ layer, with an electron concentration of $\sim 6 \times 10^{16} \mathrm{~cm}^{-3}$ and of $\sim 4 \times 10^{20} \mathrm{~cm}^{-3}$, respectively, were grown on the $\mathrm{ZnO}: \mathrm{N}$ layer by sputtering deposition. Ohmic contacts of $\mathrm{Ni} / \mathrm{Al}$ and $\mathrm{Al}$ were then fabricated on the $n^{+}-\mathrm{ZnO}$ and $\mathrm{Si}$ substrate, respectively. The contact resistance for the Ni/Al should be very small, because of high-doping in the $n^{+}$-ZnO:Al layer. By using the two-terminal method on two contacts (area of $\sim 4 \mathrm{~mm}^{2}$ ) with a spacing of $0.5 \mathrm{~mm}$, we checked the total resistance for the $\mathrm{Al}$ on $\mathrm{Si}$, which consists of the resistance of the $\mathrm{Si}$ substrate and the contact resistance. The total resistance decreases from $80 \Omega$ at $300 \mathrm{~K}$ to $52.5 \Omega$ at $150 \mathrm{~K}$, which means a negligible contact resistance, since the decrease of the total resistance is mainly due to the temperature dependence of the electrical properties of the $\mathrm{Si}$ substrate. Mesa $n-p$ diodes, each with a junction area of $2 \mathrm{~mm}^{2}$, were formed by wet etching. In spite of careful wet etching of the $\mathrm{Si}$ substrate, a thin $\mathrm{SiO}_{2}$ layer will be formed at the interface of the $\mathrm{ZnO}: \mathrm{N} / p-\mathrm{Si}$. The formation of $\mathrm{SiO}_{2}$ at the interface was tested by $\mathrm{x}$-ray diffraction (XRD) on a sample with a 


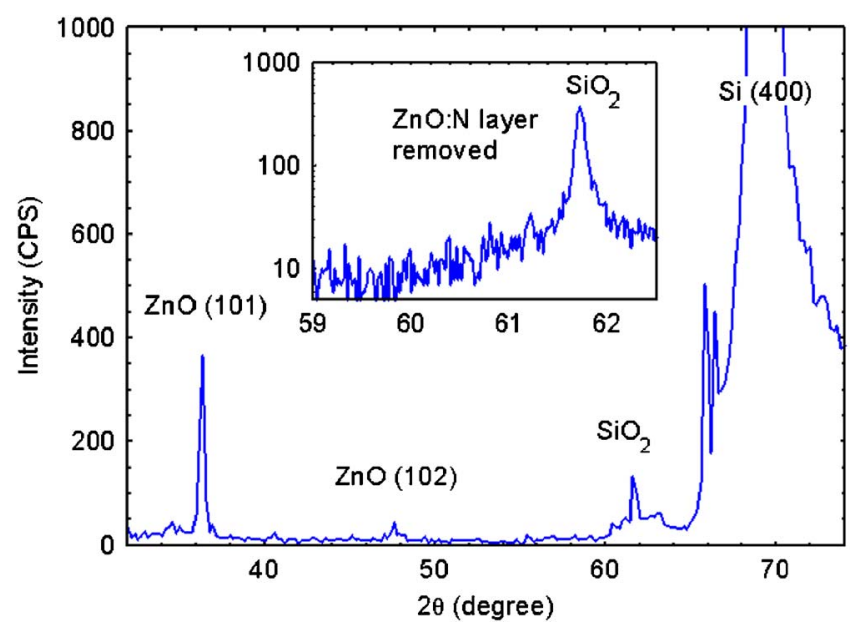

FIG. 1. XRD data of $\mathrm{ZnO}: \mathrm{N}$ on $p$-Si. The inset shows existence of $\mathrm{SiO}_{2}$ feature after removing the $\mathrm{ZnO}: \mathrm{N}$ layer.

$\mathrm{ZnO}: \mathrm{N}$ layer on $p$-Si. As shown in Fig. 1, in addition to peaks related to $\mathrm{ZnO}$ (101), $\mathrm{ZnO}$ (102), and $\mathrm{Si}$ (400), we find a peak at $2 \theta=61.7^{\circ}$. According to the Joint Committee on Powder Diffraction Standards card number 14-0654, the peak is ascribed to $\mathrm{SiO}_{2}$ structure. After removing the $\mathrm{ZnO}: \mathrm{N}$ layer, the peak remains, as shown in the inset of Fig. 1. As previously reported through measurements of $\mathrm{x}$-ray photoelectron spectroscopy, ${ }^{10}$ the thickness of $\mathrm{SiO}_{2}$ at the $n-\mathrm{ZnO} / p$-Si interface was about $3 \mathrm{~nm}$ at a deposition temperature of $480{ }^{\circ} \mathrm{C}$. Thus, we have good evidence for the existence of a thin $\mathrm{SiO}_{2}$ layer at the $\mathrm{ZnO}: \mathrm{N} / p$-Si interface during MOCVD growth at $400{ }^{\circ} \mathrm{C}$; however, it is clear that the thin $\mathrm{SiO}_{2}$ layer did not cause a problem in obtaining $n$ $-p$ diodes with reasonably good electrical characteristics for the DLTS tests. Current-voltage $(I-V)$, capacitance-voltage $(C-V)$, and DLTS measurements were measured using a digital Accent DL8000 spectrometer, with 1-MHz and $100-\mathrm{mV}$ test signals, and a Keithley 617 programmable electrometer. The DLTS spectra were obtained from Fourier transforms of the capacitance transients recorded as a function of temperature. The carrier concentration profile was derived from the $C-V$ data.

\section{RESULTS AND DISCUSSION}

To avoid possible persistent photoconductivity (PPC) induced by room light during sample mounting, the $n$-p-diode sample was kept in the dark for a few hours before the measurements. ${ }^{11}$ Actually, unlike the case of bare $\mathrm{ZnO}$ samples, the mesa $n-p$ diodes with $\mathrm{Ni} / \mathrm{Al}$ Ohmic contacts on top of the $\mathrm{ZnO}$ :Al layer do not show serious PPC at room temperature. Typical $I-V$ characteristics of the $n-p$ diodes, measured at temperatures from 200 to $400 \mathrm{~K}$, are shown in Fig. 2. The reverse current shows significant temperature dependence, indicating that thermionic emission is the dominant conduction mechanism. At $300 \mathrm{~K}$, the reverse current can be as low as $2 \times 10^{-9}$ A at a bias of $U_{R}=-1 \mathrm{~V}$, which is much lower than that reported for a Pd-Schottky diode sample [cf. sample A, Fig. 1(a), Ref. 8]. At these temperatures, the forward current at low bias $\left(U_{R}<0.5 \mathrm{~V}\right)$ can be well described by $I_{F}=I_{0}[\exp (q V / n k T)-1]$, where $I_{0}$ is the

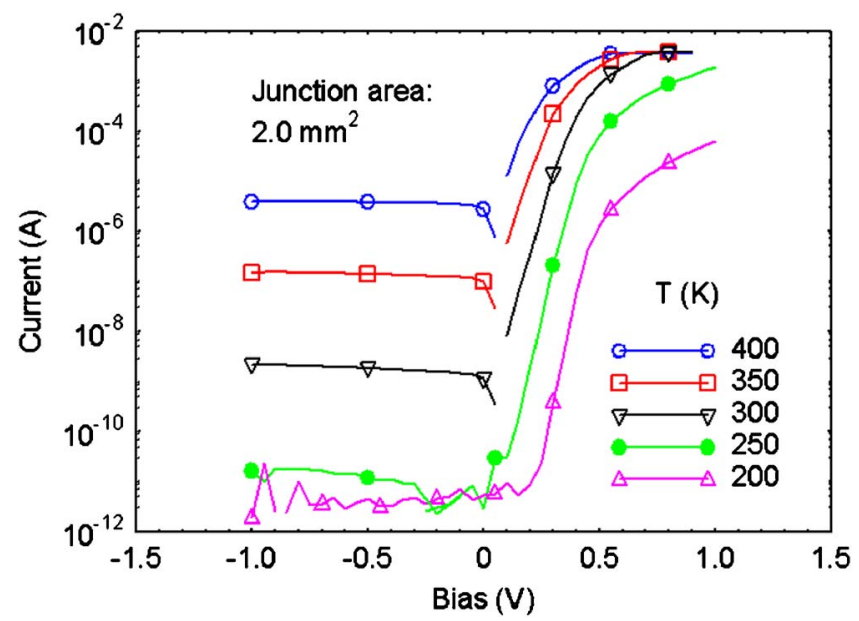

FIG. 2. Temperature-dependent $I-V$ characteristics on a $n^{+}-p$ junction diode of structure $n^{+}-\mathrm{ZnO}: \mathrm{Al} / i-\mathrm{ZnO} / \mathrm{ZnO}: \mathrm{N} / p-\mathrm{Si}$.

reverse saturation current and $n$ is the ideality factor (close to unity). From thermionic emission theory, $I_{0}$ is given by $I_{0}$ $=S A^{*} T^{2} \exp \left(-\Phi_{b} / k T\right)$, where $S$ is the diode area, $A^{*}$ is the effective Richardson constant, and $\Phi_{b}$ is the potential barrier height. Thus, an Arrhenius plot of $I_{0} / S T^{2}$ vs $1 / T$ can be used to yield $\Phi_{b}$ and $A^{*}$. By applying such an analysis for the exponential portion of the forward currents, it is found that $\Phi_{b}=0.73 \mathrm{eV}$ and $A^{*}=1.3 \mathrm{~A} \mathrm{~cm}^{-2} \mathrm{~K}^{-2}$. The value of $\Phi_{b}$ is close to values of built-in potential reported on an $n-\mathrm{ZnO} / p-\mathrm{Si}$ heterojunction prepared by chemical spray pyrolysis. ${ }^{12}$ This value of $A^{*}$ is much smaller than the theoretical value of $32 \mathrm{~A} \mathrm{~cm}^{-2} \mathrm{~K}^{-2}$ calculated for $\mathrm{ZnO}$ under the assumption that $m_{e}^{*}=0.27 m_{0}$, where $m_{0}$ is the electron mass. The significant difference could be due to the existence of a very thin $\mathrm{SiO}_{2}$ barrier at the $\mathrm{ZnO}: \mathrm{N} / p-\mathrm{Si}$ interface, through which the electrons must tunnel, as discussed by Hacke et al. in connection with the much lower value of $A^{*}$ found on $n$-GaN Schottky barrier diodes. ${ }^{13}$ Interestingly, the forward current at higher biases, where the current is limited by series resistance, decreases as temperature decreases. The reason may well involve carrier freeze-out in the $\mathrm{ZnO}: \mathrm{N}$ layer, which has been confirmed by temperature-dependent measurements of dark current in a $\mathrm{ZnO}: \mathrm{N}$ layer grown on sapphire in a separate run. The dark current for the $\mathrm{ZnO}: \mathrm{N} /$ sapphire sample, measured under a bias of $1 \mathrm{~V}$ from 400 to $100 \mathrm{~K}$, was found to decrease by about two orders of magnitude. Although the $\mathrm{ZnO}: \mathrm{N}$ layer grown on glass was reported to be $p$ type with a hole concentration of $\sim 10^{14} \mathrm{~cm}^{-3}$, the $\mathrm{ZnO}: \mathrm{N} /$ sapphire sample exhibits $n$-type behavior with a sheet concentration of $2 \times 10^{13} \mathrm{~cm}^{-2}$ at 300 $\mathrm{K}$. We are not sure of the exact electrical nature of the $\mathrm{ZnO}: \mathrm{N}$ layer in the $n^{+}-\mathrm{ZnO}: \mathrm{Al} / i-\mathrm{ZnO} / \mathrm{ZnO}: \mathrm{N} / p-\mathrm{Si}$ structure.

Typical $C-V$ characteristics of the $n-p$ diodes, measured at temperatures from 200 to $400 \mathrm{~K}$, are shown in Fig. 3. The inset in Fig. 3 shows the carrier concentration profile at $300 \mathrm{~K}$. From the inset, we see that: (i) in the region from $0.6 \mu \mathrm{m}$ up to more than $2 \mu \mathrm{m}$, which is in the $p$-Si substrate, the carrier profile is almost flat $\left(p \sim 1 \times 10^{15} \mathrm{~cm}^{-3}\right)$ and (ii) there is a clear increase of carrier concentration up to 


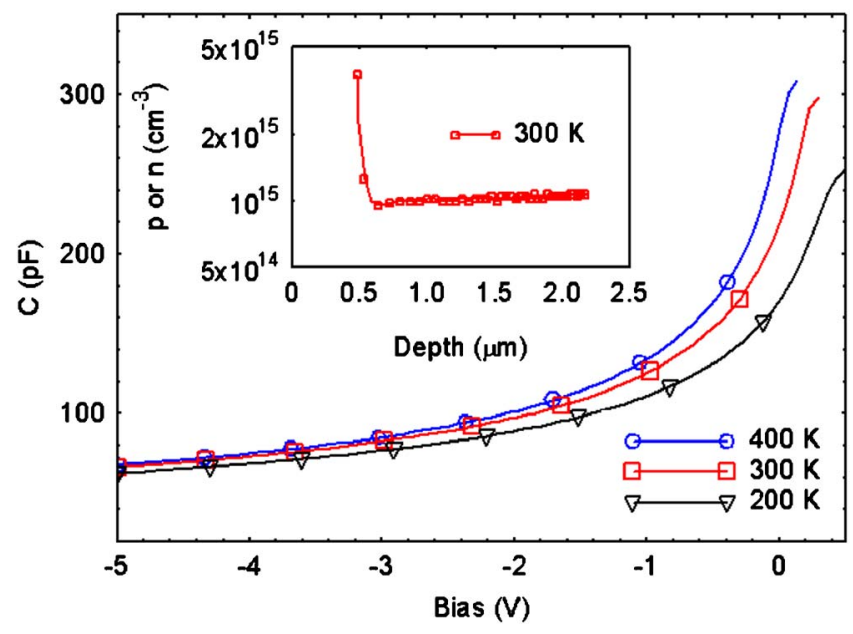

FIG. 3. Temperature-dependent $C-V$ characteristics on the $n^{+}-p$ diode. The inset shows carrier concentration profile at $300 \mathrm{~K}$.

mid- $10^{15} \mathrm{~cm}^{-3}$ at a depth of about $0.5 \mu \mathrm{m}$, which roughly corresponds to the interface between the $\mathrm{ZnO}: \mathrm{N}$ and the $p$-Si. Thus, we speculate that the $\mathrm{ZnO}: \mathrm{N}$ layer in the structure might be $n$ type; otherwise we would see a profile related to the $\sim 0.3$ - $\mu$ m-thick $p$-type $\mathrm{ZnO}: \mathrm{N}$ layer at depths of around $0.5 \mu \mathrm{m}$, before approaching the $n$-type $i$ - $\mathrm{ZnO}$ layer. The $C$ $-V$ characteristics show significant temperature dependence of the capacitance (i.e., decrease of capacitance with decreasing temperature) at biases close to zero voltage (both above and below), which likely indicates a decreasing contribution to the capacitance from the depletion region in the $\mathrm{ZnO}: \mathrm{N}$ layer due to carrier freeze-out. The potential barrier at the junction can also be measured by $C-V$ characteristics, since an approximately linear relationship of $1 / C^{2}$ vs $U_{R}$ was obtained at temperatures from 200 to $400 \mathrm{~K}$ (not shown here). At $300 \mathrm{~K}$, the intercept with the $x$ axis at $1 / C^{2}=0$ is $0.5 \mathrm{~V}$, from which a barrier height of $0.76 \mathrm{eV}$ is obtained. These results indicate that the diode is an abrupt $n^{+}-p$ junction, with the depletion region mainly in the $p$-Si substrate.

In the $n^{+}-p$ diode, the $n$-region (including both $n^{+}-\mathrm{ZnO}: \mathrm{Al}$ and $i-\mathrm{ZnO}$ thin layers) has a higher carrier concentration than the $p$ region (consisting mainly of the $p$-Si substrate). The $\mathrm{ZnO}: \mathrm{N}$ layer, which seems to be $n$ type, serves as a transition region. Detection of hole traps in the $p$-Si region can be accomplished by setting a reverse bias $\left(U_{R}\right)$ and limiting the filling pulse height $\left(U_{P}\right)$ to values near zero, while detection of electron traps in the $\mathrm{ZnO}: \mathrm{N}$ region is carried out by keeping a fixed reverse bias and then increasing the filling pulse height to forward voltages (i.e., above zero). DLTS spectra, using fixed $U_{R}=-3 \mathrm{~V}$ and changing $U_{P}$ from -0.8 to $0 \mathrm{~V}$ or from 0.2 to $0.55 \mathrm{~V}$, are pictured in Figs. 4(a) and 4(b), respectively. As seen in Fig. 4(a), two hole traps $(\mathrm{H} 3$ and $\mathrm{H} 4)$ can be observed when $U_{P}$ is set at -0.8 and $-0.4 \mathrm{~V}$, which corresponds to a trap-detection region within the $p$-Si substrate. However, when $U_{P}$ is set to $0 \mathrm{~V}$, a third trap (H5) appears, and H3 and H4 become more prominent because of a larger detection region. Evidently, H3 and $\mathrm{H} 4$ are produced by hole traps located in the $p$-Si region, while $\mathrm{H} 5$ arises from a trap located in the transition region, i.e., in the $\mathrm{ZnO}: \mathrm{N}$ layer. When the forward filling pulses are
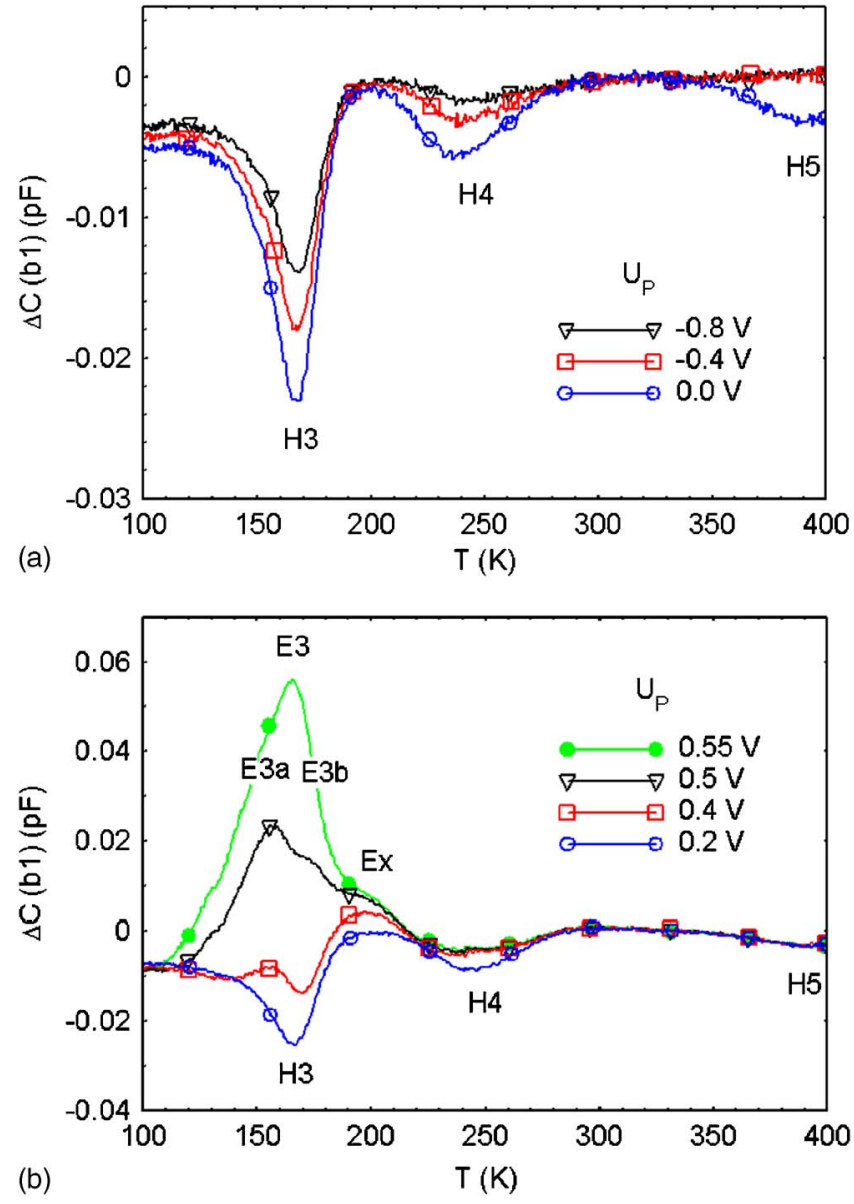

FIG. 4. DLTS spectra for the $n^{+}-p$ diode, measured with constant reverse bias $U_{R}=-3 \mathrm{~V}$, and (a) negative filling pulse heights $\left(U_{P}\right.$ 's) for hole injection and (b) positive filling pulse heights for electron injection. The other parameters were: filling pulse length $t_{P}=1 \mathrm{~ms}$ and measurement period $T_{W}=20.48 \mathrm{~ms}$.

kept in the range $0.2-0.55 \mathrm{~V}$, where the forward current increases exponentially, electron injection from the $n-\mathrm{ZnO}$ region is realized. As seen in Fig. 4(b), as $U_{P}$ is gradually increased and more electrons are injected, an electron trap (E3) with a shoulder feature (Ex) can be clearly observed. Obviously, E3 consists of two components, E3a and E3b, as seen from the spectrum measured at $U_{P}=0.5 \mathrm{~V}$.

Since the thin $\mathrm{ZnO}: \mathrm{N}$ layer was grown on the $p$-Si substrate, it can be seen as a "surface layer" on the $p$-Si. Thus, we can apply a technique, which was developed to judge whether traps are distributed through out the depletion region (bulk-like) or are concentrated near the "surface." 14 The DLTS peak height for a given trap is measured as a function of applied bias, while keeping the filling pulse height constant. With increasing $U_{R}$, a bulk trap signal will increase and a surface trap signal will decrease. DLTS spectra, measured under different biases, keeping $U_{P}=0 \mathrm{~V}$ (to observe hole traps) or $U_{P}=0.55 \mathrm{~V}$ (to observe both electron and hole traps), are presented in Figs. 5(a) and 5(b). In Fig. 5(a), we see that with increasing $U_{R}$, the trap signals of $\mathrm{H} 3$ and $\mathrm{H} 4$ increase and the trap signal of $\mathrm{H} 5$ decreases, which suggests that $\mathrm{H} 3$ and $\mathrm{H} 4$ are bulk traps in the $p$-Si, and trap $\mathrm{H} 5$, has a surface nature, i.e., is located in the $\mathrm{ZnO}: \mathrm{N}$ layer. From Fig. 5(b), we find that electron trap E3, composed of E3a and 

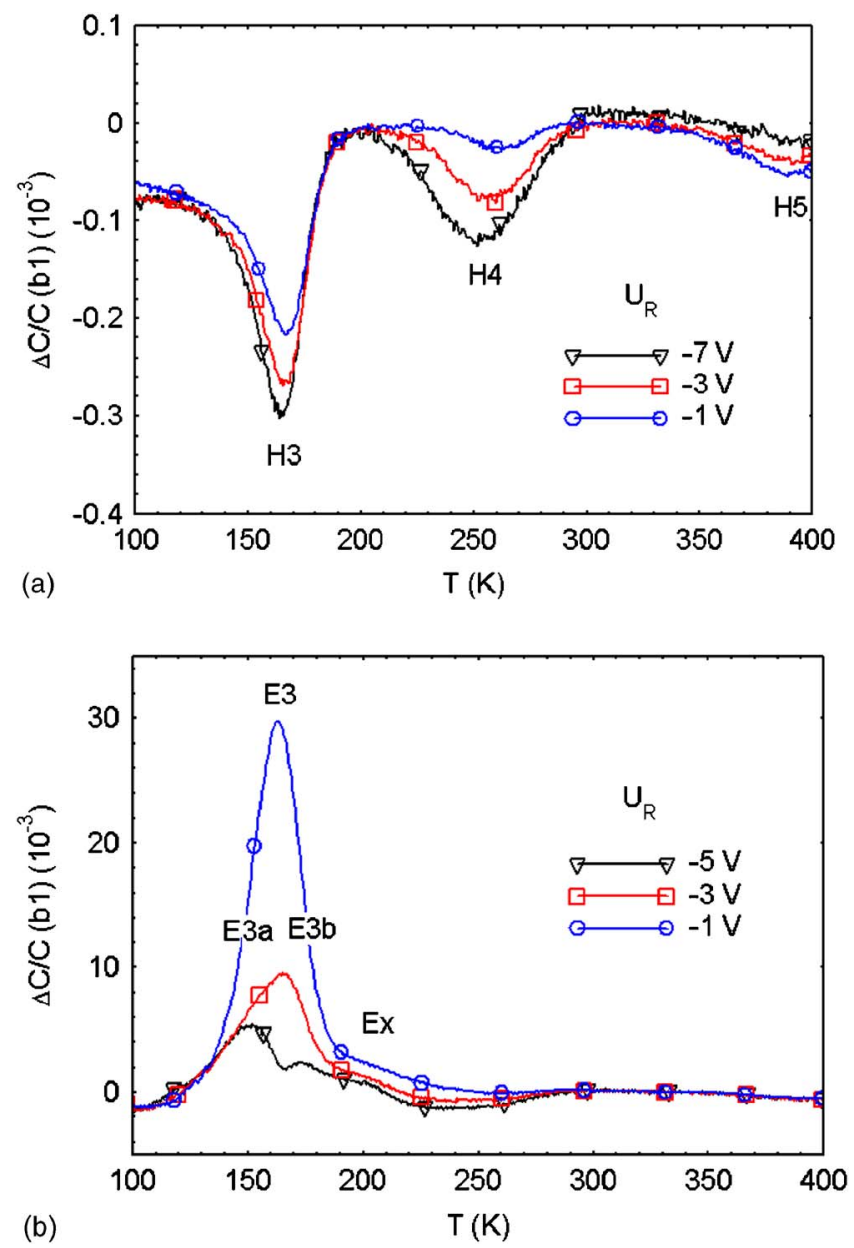

FIG. 5. DLTS spectra for the $n^{+}-p$ diode, measured with (a) $U_{P}=0$ and variable $U_{R}$; and (b) $U_{P}=0.55 \mathrm{~V}$ and variable $U_{R}$. The other parameters were: $t_{P}=1 \mathrm{~ms}$, and $T_{W}=20.48 \mathrm{~ms}$.

E3b, decreases when $U_{R}$ increases, which implies that this trap is also located in the thin $\mathrm{ZnO}: \mathrm{N}$ layer. It appears that E3a has a larger capture cross section than E3b, when a higher bias (or electric field) is applied.

By using "maximum evaluation," a software designed for analysis of trap parameters, the activation energy and apparent capture cross section for the major DLTS traps are determined to be: $0.29 \mathrm{eV}$ and $4.4 \times 10^{-16} \mathrm{~cm}^{2}$ for E3; 0.35 $\mathrm{eV}$ and $7.4 \times 10^{-14} \mathrm{~cm}^{2}$ for $\mathrm{H} 3 ; 0.48 \mathrm{eV}$ and 2.9 $\times 10^{-15} \mathrm{~cm}^{2}$ for $\mathrm{H} 4$; and $0.9 \mathrm{eV}$ and $4 \times 10^{-14} \mathrm{~cm}^{2}$ for $\mathrm{H} 5$, respectively. The electron trap E3, with an activation energy of $0.29-0.30 \mathrm{eV}$, has been previously reported for all bulk $\mathrm{ZnO}$ (Refs. 5-7) and is thought to be related to oxygen vacancies, $V_{\mathrm{O}}$. Actually, the presence of two components in the trap E3 has been clearly revealed by high-resolution Laplace DLTS characterization. ${ }^{7}$ However, in vapor transport grown $\mathrm{ZnO}$ bulk crystals, a deep center E4 at $0.53 \mathrm{eV}$ below the conduction band was found to decrease after oxygen annealing and thus has been assigned to $V_{\mathrm{O}}{ }^{15}$ On the other hand, in a recent study of as-grown and $\mathrm{N}^{+}$-implanted $\mathrm{ZnO}$ single crystals, E3 has been assigned to $\mathrm{Zn}_{i}{ }^{16}$ The hole trap H3, with activation energy of $0.35 \mathrm{eV}$, could be related to transition metals in the $p$-Si, or $\mathrm{Zn}$ that might have diffused into the $p$-Si during growth of the $\mathrm{ZnO}$ films. ${ }^{17}$ It should also be mentioned that a Li-acceptor-related hole trap $A_{3}$, with acti-

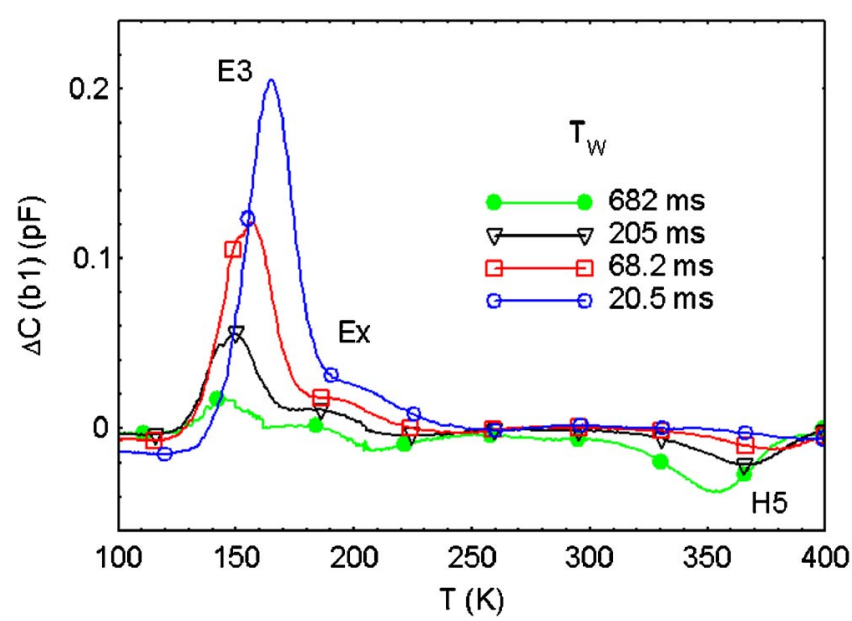

FIG. 6. DLTS spectra for the $n^{+}-p$ diode as a function of measurement period $T_{W}$. The other parameters were: $U_{R}=-1 \mathrm{~V}, U_{P}=0.5 \mathrm{~V}, t_{P}=1 \mathrm{~ms}$, and $T_{W}=20.48 \mathrm{~ms}$.

vation energy of $0.28 \mathrm{eV}$ and capture cross section of $\sim 10^{-16} \mathrm{~cm}^{2}$, was reported in pressurized melt-grown $\mathrm{ZnO}$ using a $p-n$ junction diode formed by $\mathrm{N}^{+}$-implantation; $;^{8}$ on the other hand, we have no evidence for $\mathrm{Li}$ in our sample. The hole trap H4, with an activation energy of $0.48 \mathrm{eV}$, could also be due to transition metals in $p$-Si. ${ }^{17}$ However, a further understanding of $\mathrm{H} 3$ and $\mathrm{H} 4$ will require a DLTS study of the $p$-Si substrate itself. A preliminary measurement, which was performed on a $p$-Si Schottky diode (with the $\mathrm{ZnO}$ :N layer removed), shows the existence of $\mathrm{H} 3$. The hole trap H5, with an activation energy of $0.9 \mathrm{eV}$, has been observed in the $\mathrm{ZnO}: \mathrm{N}$ layer. The $0.9-\mathrm{eV}$ hole trap was reported in vapor transport grown bulk $\mathrm{ZnO}$, for both a virgin sample and a sample implanted with $100-\mathrm{keV}$ protons. ${ }^{18}$ In Ref. 18 , the authors invoked an early review that related these centers to oxygen vacancies. In contrast to the behavior of the other traps, the DLTS signal of H5 shows an anomalous increase as the measurement period $T_{W}$ increases (or the "rate window" decreases), as shown in Fig. 6. Sometimes a decrease of the DLTS signal with decreasing rate window is observed and this effect is usually attributed to a capture barrier, such as might be associated with threading dislocations. ${ }^{19}$ Further DLTS investigations will be needed to understand the peculiar capture behavior of trap H5.

\section{CONCLUSIONS}

A $n^{+}-p$ diode, consisting of $n+-\mathrm{ZnO}: \mathrm{Al} / i-\mathrm{ZnO} /$ $\mathrm{ZnO}: \mathrm{N}$ layer grown on $p-\mathrm{Si}$, has been used to investigate electron and hole traps in the $\mathrm{ZnO}: \mathrm{N}$ layer. The temperature-dependent $I-V$ and $C-V$ characteristics show that the diode has an abrupt junction with a potential barrier of $0.75 \mathrm{eV}$. When holes are injected by reverse biasing the diode, three hole traps, H3 $(0.35 \mathrm{eV}), \mathrm{H} 4(0.48$ $\mathrm{eV})$, and $\mathrm{H} 5(0.9 \mathrm{eV})$, are observed; also, one electron trap E3 $(0.29 \mathrm{eV})$ is revealed by injecting electrons. Following the results of previous studies, E3 could be related to oxygen vacancies or zinc interstitials, while $\mathrm{H} 3$ and $\mathrm{H} 4$ could 
be due to impurities in the $p$-Si. A hole trap, $\mathrm{H} 5(0.9 \mathrm{eV})$, is observed in the $\mathrm{ZnO}: \mathrm{N}$ layer; however, it displays a peculiar capture behavior.

\section{ACKNOWLEDGMENTS}

The work of Z.-Q.F., B.C., and D.C.L. was supported by USARO Grant No. DAAD19-02-D-0001 (M. Gerhold), NSF Grant No. DMR0513968 (L. Hess), SVTA Subcontract No. W911NF-06-C-0015 (A. Osinsky), and USAFOSR Grant No. F49620-03-1-0197 (K. Reinhardt).

${ }^{1}$ A. Kobayashi, O. F. Sankey, and J. D. Dow, Phys. Rev. B 28, 946 (1983). ${ }^{2}$ S. J. Pearton, D. P. Norton, K. Ip, Y. W. Heo, and T. Steiner, Prog. Mater. Sci. 50, 293 (2005).

${ }^{3}$ T. J. Coutts, D. L. Young, and X. Li, Mater. Res. Soc. Symp. Proc. 623, 199 (2000)

${ }^{4}$ X. Li, Y. Yan, T. A. Gessert, C. L. Perkins, D. Young, C. Dehart, and T. J. Coutts, J. Vac. Sci. Technol. A 21, 1342 (2003).

${ }^{5}$ J. C. Simpson and J. F. Cordaro, J. Appl. Phys. 63, 1781 (1988).

${ }^{6}$ F. D. Auret, S. A. Goodman, M. J. Legodi, W. E. Meyer, and D. C. Look, Appl. Phys. Lett. 80, 1340 (2002).

${ }^{7}$ F. D. Auret, J. M. Nel, M. Hayes, L. Wu, W. Wesch, and E. Wendker, Superlattices Microstruct. 39, 17 (2006).
${ }^{8}$ H. von Wencksten, R. Pickenhain, H. Schmidt, B. Brandt, G. Biehne, M. Lorenz, M. Grundmann, and G. Brauer, Appl. Phys. Lett. 89, 092122 (2006).

${ }^{9}$ X. Li, S. E. Asher, S. Limpijumnong, B. M. Keyes, C. L. Perkins, T. M. Bernes, H. R. Moutinho, J. M. Luther, S. B. Zhang, S.-H. Wei, and T. J. Coutts, J. Cryst. Growth 287, 94 (2006).

${ }^{10}$ Y. S. Choi, J. Y. Lee, W. H. Choi, H. W. Yeom, and S. Im, Jpn. J. Appl. Phys., Part 1 41, 7357 (2002).

${ }^{11}$ B. Claflin, D. C. Look, S. J. Park, and G. Cantwell, J. Cryst. Growth 287, 16 (2006).

${ }^{12}$ R. Romero, M. C. López, D. Leinen, F. Martín, and J. R. Ramos-Barrado, Mater. Sci. Eng., B 110, 87 (2004).

${ }^{13}$ P. Hacke, T. Detchprohm, K. Hiramatsu, and N. Sawaki, Appl. Phys. Lett. 63, 2676 (1993).

${ }^{14}$ D. C. Look and Z.-Q. Fang, Appl. Phys. Lett. 79, 84 (2001).

${ }^{15}$ D. Pfisterer, D. M. Hofmann, J. Sann, B. K. Meyer, R. Tena-Zaera, V. Munoz-Sanjose, Th. Frank, and G. Pensl, Physica B (Amsterdam) 376377, 767 (2006)

${ }^{16}$ G. Brauer, W. Anwand, W. Skorupa, J. Kuriplach, O. Melikhova, and C. Moisson, Phys. Rev. B 74, 045208 (2006).

${ }^{17}$ J.-W. Chen and A. G. Milnes, Annu. Rev. Mater. Sci. 10, 157 (1980).

${ }^{18}$ A. Y. Polyakov, N. B. Smirnov, A. V. Govorkov, E. A. Kozhukhova, V. I. Vdovin, K. Ip, M. E. Overberg, Y. W. Heo, D. P. Norton, S. J. Pearton, J. M. Zavada, and V. A. Dravin, J. Appl. Phys. 94, 2895 (2003).

${ }^{19}$ Z.-Q. Fang, D. C. Look, and L. Polenta, J. Phys.: Condens. Matter 14, 13061 (2002). 